\title{
IMPACT OF THE METHOD OF REGISTERING TERRESTRIAL LASER SCANNING DATA ON THE QUALITY OF DOCUMENTING CULTURAL HERITAGE STRUCTURES
}

\author{
M. Kedzierski ${ }^{\text {a }}$, A.Fryskowska ${ }^{\text {* }}$, D. Wierzbicki ${ }^{\text {a }}$, M. Dabrowska ${ }^{\text {a }}$, A. Grochala ${ }^{\text {a }}$ \\ ${ }^{a}$ Department of Remote Sensing and Photogrammetry, Geodesy Institute, Faculty of Civil Engineering and Geodesy, Military \\ University of Technology, Warsaw, Poland - (mkedzierski, afryskowska, dwierzbicki)@wat.edu.pl, duchadynka@wp.pl, \\ olagrochala@wp.pl
}

Commission III, WG III/2

KEY WORDS: Airborne Laser Scanning, Data Fusion, Accuracy, Point Cloud, Heritage Documentation, 3D Transformation

\begin{abstract}
:
When documenting historical structures and objects, especially delicate artefacts such as pieces of sacred art, only techniques that allow remote, non-contact methods that enable the most precise measurements should be used to obtain data. TLS can be considered as such a technique however in order to obtain complete information for the entire structure, there is usually a need to acquire data from more than one measuring station. In this case, the most important and essential step of processing TLS data is the registration of scans. The paper contains a description of research and analyses concerning the registration of point clouds using three methods: manual, automatic and a combination of the two. The research was carried on measurement data from a historical synagogue. The structure was divided into three parts - three scans. The accuracy with which these scans were registered was assessed and a 3D model of the interior was created.
\end{abstract}

\section{INTRODUCTION}

The registration of scans can be conducted in three different ways: by automatically matching corresponding points directly identified by the operator (target-to-target registration); by manually matching corresponding pseudo-homogeneous points (cloud-to-cloud orientation); by using a so-called combined method, utilizing both methods simultaneously. (Van Genechten et al., 2008)

The target-to-target method consists of determining the matching parameters of one scan to another using at least three reference points selected by the operator. Usually a greater number of homologous points are needed so that the least squares method could be applied in order to lower the transformation errors (Van Genechten et al., 2008).

The cloud-to-cloud method differs from the previously described method in that the transformation parameters are determined from points of a point cloud located close to the points selected by the operator. The operator selects at least three homologous points in both data sets, which are used to perform a coarse registration. More precise transformation parameters are then obtained in an iterative manner by generating pairs of corresponding points adjacent to those selected earlier and thus minimizing errors. This method requires an point cloud overlap of $30-40 \%$. (Van Genechten et al., 2008).

The surface-to-surface method registers scans by matching the surfaces. It is based on performing an estimation of the transformation parameters for one or a number of surfaces in relation to a reference surface using a generalized GaussMarkoff model, minimizing the sum of the squares of the Euclidean distances between the surfaces (Gruen A., Akca D, 2005). This process is done iteratively and requires at least three reference points for an initial registration.
Registration methods can also be grouped in terms of the chosen reference points. This choice can be based on (Kedzierski et al., 2010), (Kedzierski, Fryskowska, 2014):

- using detailed scan points, which had been signalized during the measurements (choice of targets) - automatic method.

- visually interpreting edges and corners of characteristic structures occurring within the point cloud - manual method.

- using both signalized targets and points of the cloud combined method.

The following section describes an analysis of the impact of the above mentioned registration methods on the resulting accuracy of data, forming the basis of architectural documentation.

\section{RESEARCH}

\subsection{Source data}

The following research is based on scans taken of the interior of a synagogue. Measurements were taken using the Leica ScanStation 2 impulse scanner. Measurements of the interior were taken from 18 measurement stations, 7 of which were located on the ground floor, 8 located on the balconies, and 3 located on the stairs between the two floors. (Fig. 1)

\footnotetext{
* Anna Fryskowska afryskowska@ wat.edu.pl
} 

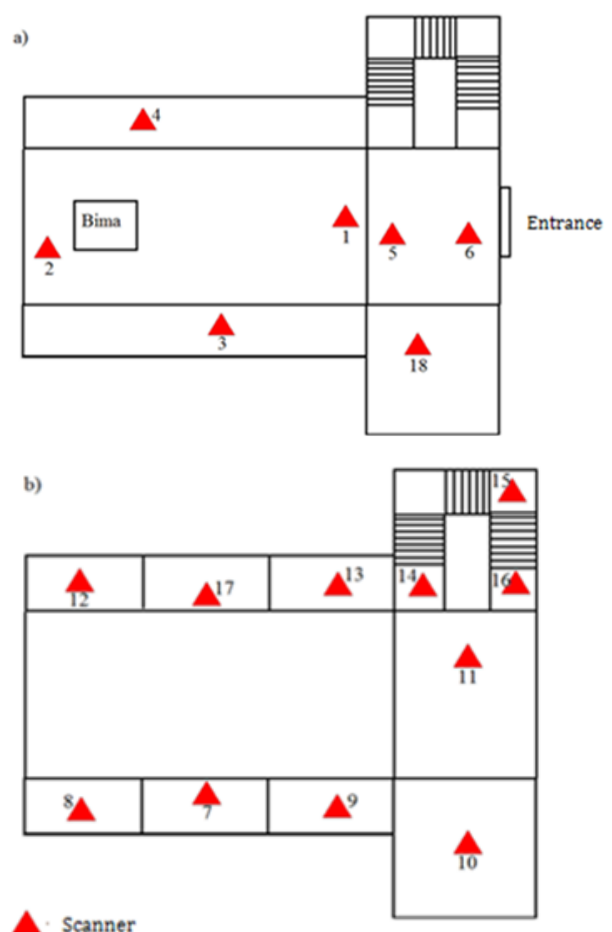

location symbol

Figure 1. Diagram showing the location of measurement stations in the interior of the synagogue: a) on the ground floor, and b) on the balconies

Scans 1 to 4 were acquired from measuring stations located in the main area of the synagogue at ground level, measuring points not only on the ground level, but also those located on the balconies and the ceiling. Scans 5 and 6 are the result of measurements taken of the synagogue vestibule that is connected to the main area by a set of doors. Point clouds from stations 7 to 13 gathered information about objects located in different parts of the balconies, this however does not include data from objects and structures located on the ground floor; such points are found on scan 17, which was acquired by a scanner located on one of the balconies. At this location the instrument was able to acquire data from objects located on both the upper and lower levels. Additionally, scan 17 partially overlaps with scan 18 that is the result of scanning the library located on the ground floor. Point clouds from stations 14 to 16 are the result of measuring the stairs linking the two floors. They are connected to the ground floor doors leading up to the balconies.

\subsection{Measurements}

The process of joining all of the scans of the interior was divided into 3 stages. The first stage required joining the scans of the ground level, scanned from stations 1 to 7 . The second stage involved joining scans 14 to 16 of the stairs. The third stage joined scans 8 to 13 , and 17 of the balconies together with the library (scan 18).

Before registering the scans, 17 check planes were determined, whose location after the transformation would be used as a measure of the matching process. Objects with regular surfaces and easily identifiable edges were chosen from the point clouds as control surfaces.
Examples of control surfaces have been shown in figure 2, with their spatial distribution shown in figure 3

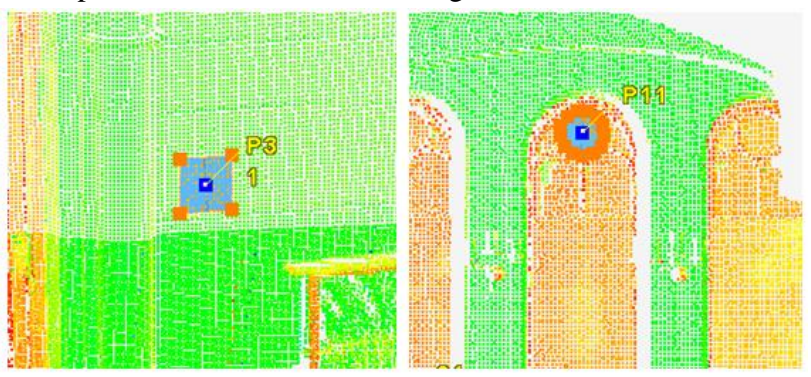

Figure 2. Example of rectangular and circular control surfaces.

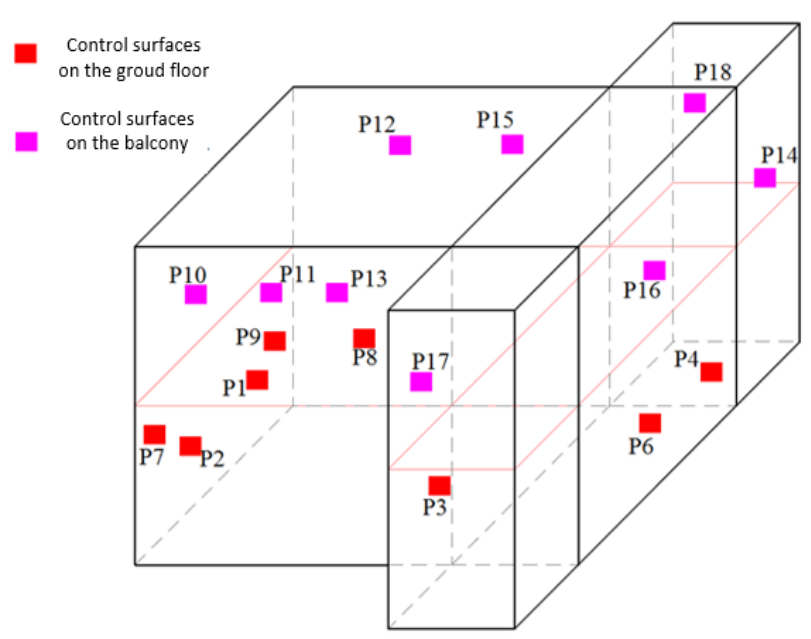

Figure 3. Spatial distribution of control surfaces

Scans from the first stage were registered using both the automatic and manual method. These were conducted with a mean absolute error equal to $1 \mathrm{~mm}$. The deviation limits are equal to 0.7 of the value of the approximate resolution of the point cloud, from which the control surfaces were modelled. The resulting registration parameters were also compared. This was made possible by transforming all scans to one local coordinate system from measuring station 1 . The translation parameters of the corresponding coordinate systems' origins are in both cases either identical or very similar - the deviation reaching $3 \mathrm{~mm}$ (transformation of the scan from station 6). By analysing the rotation parameters, it can be determined that the maximum discrepancy was equal to $0.016^{\circ}$ (station 7).

The scans from the upper level of the synagogue were also registered using the automatic and manual methods, however in this case the resulting transformation errors were no longer identical to those found at the lower level. The mean absolute error for the automatic method was equal to $1 \mathrm{~mm}$, with the maximum error for any one target reaching $3 \mathrm{~mm}$.

When performing the registration manually, the mean absolute error was $10 \mathrm{~mm}$. This value is ten times greater than when the registration was done automatically. This result was also verified using the control surfaces. The differences in the distances between the centres of these control surfaces were determined for both methods, having insignificant values around $1-2 \mathrm{~mm}$.

During the third stage, data was registered using the manual and combined methods. The mean absolute error of this process was $1 \mathrm{~mm}$. For the combined method, the maximum error for any 
target did not exceed $1 \mathrm{~mm}$, similar to the manual method. Both methods gave the same translation parameters and negligible differences in the rotation parameters. The mean deviation between the centres of the control surfaces in both cases was equal to $14 \mathrm{~mm}$.

Such similar results for the combined and manual methods are a consequence of the very good resolution of the point clouds (around $2.5 \mathrm{~cm}$ ), and the relatively small distance between the scanned objects and the scanner. Using the registered point clouds, a 3D model of the synagogue's interior was generated. The accuracy of the resulting model was also analyzed based on reference measurements. The mean absolute difference between selected 3D model measurements of linear elements (edges) compared to their actual lengths did not exceed $1.8 \mathrm{~cm}$. The maximum difference was equal to $4.5 \mathrm{~cm}$.

At least three evenly distributed pairs of points were used to register each of the point clouds representing the entire interior. The point cloud created as a result of the described registration is shown in figure 4.

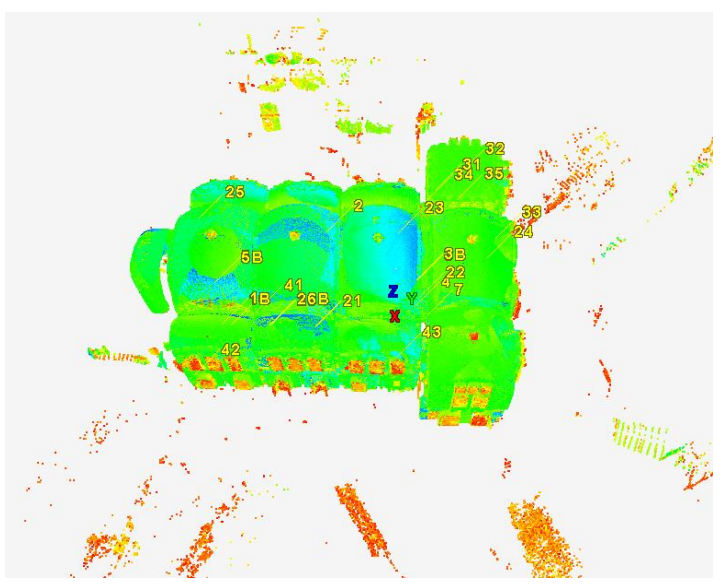

Figure 4. Point cloud resulting from registering a series of point clouds of the sygagogue interior

The results of the conducted registrations were compared with results obtained by other research groups (Kedzierski et al. 2009), (Maciaszek, 2009), (Kedzierski et al. 2010), who had also conducted automatic registrations of architectural structures obtaining mean errors of $2-3 \mathrm{~mm}$, and manual registrations (of road engineering structures) with mean errors of $7-29 \mathrm{~mm}$. These results suggest that the registration described in this paper was conducted with sufficient accuracy, especially that the obtained errors were lower than those in the above mentioned research.

\subsection{Modelling of the data}

Based on the registered point clouds a 3D model of the interior of the synagogue was generated. The result of this 3D modelling of the joint point clouds in shown in figure 5

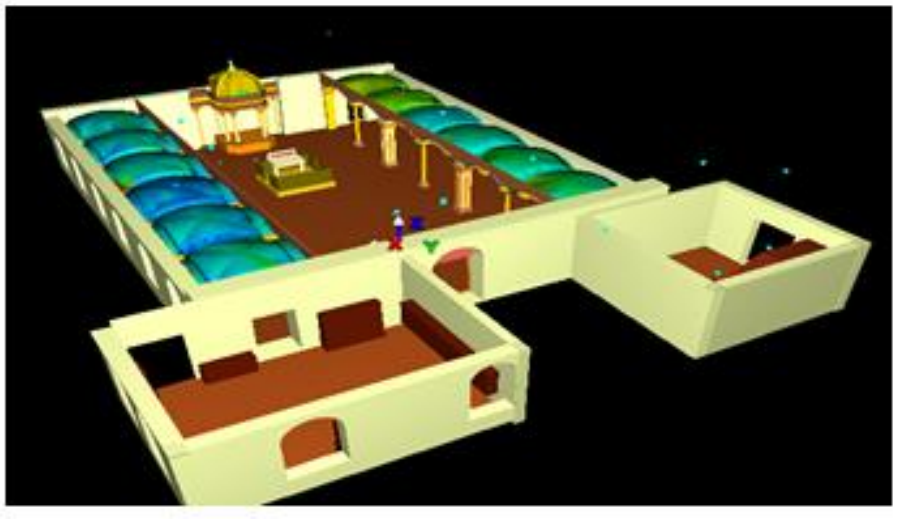

Figure 5. 3D model of the synagogue interior

The accuracy of the resulting model was also analyzed using control reference measurements. The mean absolute differences between the lengths of chosen sections of the 3D model (edges) and the actual lengths of those sections did not exceed $1.8 \mathrm{~cm}$. The maximum difference was equal to $4.5 \mathrm{~cm}$.

\section{CONCLUSIONS}

It is important to remember, that when scanning architectural structures, it is essential to ensure a measurement accuracy of a few millimetres. This is due to small dimensions and intricate shapes of decorative elements. Therefore it is essential to chose such a method of registering scans, which will ensure the greatest accuracy. Without a doubt, the automatic method utilising signalised targets meets this criterion by guaranteeing the highest accuracy and position errors not exceeding 2-3mm. Research shows, that even though the manual and combined methods give similar accuracies in good measurement conditions, both of these methods are very sensitive to uneven distributions of points and errors made by the operator during post processing, which could result in position errors of structure elements on the registered scans reaching a few centimetres.

\section{ACKNOWLEDGEMENTS}

This paper has been supported by the Military University of Technology, the Faculty of Civil Engineering and Geodesy, Department of Remote Sensing and Photogrammetry.

\section{REFERENCES}

Gruen A., Akca D., 2005, Least squares 3D surface and curve matching., ISPRS Journal of Photogrammetry and Remote Sensing 59, pp. 151- 174

Kedzierski, M.; Fryskowska, 2014, A. Terrestrial and Aerial Laser Scanning Data Integration Using Wavelet Analysis for the Purpose of 3D Building Modeling. Sensors 2014, 14, 12070-12092

Kedzierski M., Fryskowska A., Wilinska M., 2010, Naziemny skaning laserowy obiektów inżynieryjno-drogowych 
The International Archives of the Photogrammetry, Remote Sensing and Spatial Information Sciences, Volume XL-5/W7, 2015 25th International CIPA Symposium 2015, 31 August - 04 September 2015, Taipei, Taiwan

(Terrestrial Laser Scanning of hydrotechnical objects), Biuletyn WAT, Vol. LIX, Nr 2

Kedzierski M., Fryskowska A., Dabrowski R., Wilinska M., 2009, Naziemne skanowanie laserowe obiektów sakralnych z zastosowaniem technologii HDS (Terrestrial Laser Scanning of sacra structures in HDS technology), Wiadomości Konserwatorskie, tom nr 26, pp.670-678, Warsaw.

Maciaszek J., 2009, Laser scanning as a new technology of visualization and inventory of historical salt chamber, Skanowanie laserowe jako nowa technologia inwentaryzacji $i$ wizualizacji zabytkowych komór solnych. Gospodarka Surowcami Mineralnymi, T. 24, vol.3/2, p. 197-209.

Van Genechten B, Quintero M. S., 2008, Theory and practice on Terrestrial Laser Scanning.Training material based on practical applications, Valencia. 